\title{
PROCEDIMENTOS DE COMPOSIÇÃO DOS CUSTOS E DETERMINAÇÃO DO PREÇO DE VENDAS EM UMA FÁBRICA DE CAMISETAS SEM ESTAMPAS - PRODUÇÃO EM LARGA ESCALA
}

Leandro de Oliveira Arantes -Faculdade de ciências contábeis de Nova Andradina - MS ; Natália Freitas Giunco - Faculdade de ciências contábeis de Nova Andradina - MS; Maria Ester de Oliveira - Faculdades integradas de Nona Andradina - MS, Renan da Silva Costa,

Faculdades integradas de Nona Andradina - MS, Amanda Camerini Lima - Faculdades integradas de Nona Andradina - MS

leandro.o.arantes@gmail.com

\section{RESUMO}

Uma das principais atividades da contabilidade de custos consiste no trabalho de coleta de dados, processamento e transformação em informações referente a composição dos custos dos bens ou serviços, sendo de extrema relevância em qualquer empresa, seja em uma indústria, comércio ou prestadora de serviços, tal processo é essencial e decisivo para a precificação dos bens ou serviços, assegurando a entidade a margem de lucro desejada. Por isso, esse processo é substancial para as empresas, pois somente através do trabalho de levantamento de gastos relativos aos investimentos realizado, sejam em despesas, custos fixos ou variáveis, diretos ou indiretos, com possibilidade de apropriação direta ou que exijam critérios de rateios para alocação, é que se pode definir o valor justo e compatível com a produção e exigências do mercado, sejam em termos de qualidade, quantidade e preço atrativo, independente se comercializado no varejo ou no atacado, e independe do ramo de atividade. O presente trabalho de custeamento tem por vista apresentar conceitos e formas corretas para composição dos custos e precificação de um produto, a saber, camisetas sem estampas, produzidas em grande escala pela empresa ARANTES \& GIUNCO LTDA.

Palavras-chave: Ciência; Contabilidade; Gastos; Custos; Precificação

\section{INTRODUÇÃO}

A contabilidade é considerada uma ciência social que tem por finalidade o estudo da mutação e evolução do patrimônio das entidades, independentemente de serem elas pessoas físicas ou pessoas jurídicas. E, portanto, sendo a contabilidade de custos um braço dessa ciência que, de início teve como primícias o levantamento de estoques e apuração do lucro global, mas, porém, com o avanço industrial e tecnológico é considerada de suma 
importância para gestão, controle de processos e tomada de decisões relevantes pelas entidades, seja para fins de melhorias de processos, redução de custos, projeções futuras, aumento de produtividade, descontinuidade de linhas de produção, investimentos, entre outras. Então, quando o assunto é contabilidade de custos, técnica utilizada para identificar, mensurar, processar e informar os custos de bens e serviços objeto de estudo. Logo o tema em questão refere-se aos gastos que estão diretamente relacionados ao processo de produção de bens ou serviços para fins de comercialização no mercado consumidor. Através dos gastos (investimentos) é que a empresa obtém os insumos (matéria-prima, materiais secundários, embalagens, etc.) e mão de obra necessários para realização de suas atividades produtivas. Tais gastos, quando direcionados a produção são considerados custos, podendo serem classificados em diretos e indiretos, fixos ou variáveis. Crepaldi (2017, p. 20), diz que: “Custos são os gastos relativos a bens ou serviços utilizados na produção de outros bens ou serviços, sejam eles desembolsados ou não. Só são reconhecidos como custos no momento da fabricação de um produto ou execução de um serviço. ” Ainda de acordo com Eliseu Martins (2018, p. 23), custo é: "Gasto relativo a bem ou serviço utilizado na produção de outros bens ou serviços. ”No entanto, durante o processo de identificação dos gastos relativos a custos, ou seja, que estão direcionados a área de produção, tais custos recebem classificações de acordo com o grau de dificuldade de alocação aos produtos. Os custos de fácil apropriação que diretamente são identificados no produto recebem a classificação de custos diretos, exemplo: matéria-prima e mão-de-obra direta, bastando apenas existir algum critério de consumo (peso, quantidade, etc.), podendo ainda serem classificados como variáveis, ou melhor dizendo, os custos diretos são variáveis, pois além de serem diretamente alocados aos produtos, seu consumo oscila de acordo com a produção do período, quanto maior a produção, maior o consumo, á registros literários que relatam serem os custos diretos ou variáveis nulos em caso de períodos sem produção. Os custos indiretos são custo necessários para o perfeito funcionamento do processo de produção, porém não são fáceis de alocação aos produtos e que muitas vezes são consumidos por departamentos de apoio ao setor de produção, exemplo: manutenção, lavanderia, serviços de limpeza da fábrica, salários de supervisores, etc.), nesses casos são necessários algum critério de rateio para a apropriação aos produtos. Os custos fixos são gastos que não se alteram em relação ao 
volume de produção durante um determinado período, porém seu reflexo e cada vez menor por unidade produzida quando ocorre alavancagem de produção.

Diante do apresentado, esse trabalho de pesquisa, levantamento de custo e precificação do produto final foi realizado para a empresa ARANTES \& GIUNCO LTDA (futura constituição e instalação na cidade de Presidente Venceslau-SP), empresa esta voltada ao ramo de atividade de indústria do vestuário, mais especificamente na fabricação de camisetas sem estampadas. Na planilha de levantamento e composição de custos (tabela 1) também foi destacado o processo de precificação do produto, trazendo as informações com todos os gastos, custos e despesas, sendo eles direto ou indireto, fixos ou variáveis, com vistas a composição do preço de venda unitário e total, de forma a atender a margem de lucro desejada. Conforme dicio.com.br (online) precificação é: “Ação de precificar, de determinar o valor, o preço de; atribuição de valor a um produto ou serviço; avaliação: precificação de ações. "

\section{MÉTODOLOGIA}

O método utilizado para desenvolvimento deste trabalho de pesquisa, coleta de dados, processamento e triagem de custos se dará por meio de entrevistas, pesquisa e análise documental (notas fiscais, contratos, etc.), busca de informações e embasamentos legais. Será demonstrado em planilha os gastos (custos e despesas), necessário para o desenvolvimento e criação do produto final, as camisetas sem estampas.

\section{RESULTADOS E DISCUSSÕES}

A empresa ARANTES \& GIUNCO LTDA, é uma empresa em início de atividades e para precificar seu produto, as camisetas sem estampas, precisa calcular o custo unitário e custo total para elaborar um plano de negócio de vendas, seja no varejo ou atacado. Para isso foi necessário separar e organizar em planilha todos os custos e gastos diretamente ligados a produção.

A empresa, para fins de apuração de custeamento de produção e resultados, usará o método de custeio por absorção, método este que consiste na apropriação de todos os custos do período aos produtos, sejam eles diretos ou indiretos, fixos ou variáveis. Sendo este método, inclusive, o único aceito pela legislação fiscal e de imposto de renda no 
Brasil, por ser o único a respeitar os Princípios Fundamentais de Contabilidade, sendo amplamente utilizado pelas empresas para apuração de seus custos, levantamento de estoques, entre outros. E conforme Leone (2000, p. 242), “[...] o critério do custo por absorção é aquele que inclui todos os custos indiretos de fabricação de certo período nos custos de suas diferentes atividades industriais, sejam produtos, processos ou serviços".

Ainda para melhor enfatizar a importância do método de custeio por absorção, Eliseu Martins, (2018,pg. 23) diz: "Não é um princípio contábil propriamente dito, mas uma metodologia decorrente deles, nascida com a própria Contabilidade de Custos. Outros métodos diferentes têm surgido através do tempo, mas este é ainda o adotado pela Contabilidade Financeira; portanto, válido tanto para fins de Balanço Patrimonial e Demonstração de Resultados como também, na maioria dos países, para Balanço e Lucro Fiscais."

A empresa ARANTES \& GIUNCO LTDA, será constituída no município de Presidente Venceslau, Estado de São Paulo, por dois amigos, profissionais formados em Ciências Contábeis. A escolha da cidade pelos sócios da empresa, se deu, devido a grande maioria da matéria prima e insumos utilizados na produção serem oriundos das cidades estado em questão, evitando assim, impostos relativos a ICMS (diferencial de alíquota), fretes, entre outros gastos.

O objetivo da empresa é a confecção de camisetas sem estampas, com foco no mercado atacadista e intenção de produção em larga escala de camisetas de modelo único, cores variadas, para serem vendidas à grandes marcas, e estas por sua vez darem seus toques finais em estamparias, logo, agregação de etiquetas de suas grifes, etc. Porém, temse por objetivo a vendas de camisetas no varejo, numa loja própria, localizada em um dos espaços (salas) na frente da fábrica. As vendas no varejo ocorrerão com preços mais atrativos, uma por não depender de fretes, entre outros custos e também por não carregarem nomes de marcas famosas, mas apenas a etiqueta do fabricante conforme normas nacionais para indústria de confecção.

Após a captação dos dados e processamento das informações para geração da planilha de custo, foi possível apropriar todos os custos e despesas referente a produção de camisetas sem estampas. O custo da matéria prima principal, que é o tecido, foi adquirido em uma empresa especializada em fabricação e venda de tecidos no atacado com preços mais atrativos e alta qualidade do produto, tendo capacidade de fornecimento 
em grandes quantidades. Inclusive a empresa realizou cotações de preços em fornecedores diferentes, preservando a qualidade da matéria prima, optando pela de menor preço e com ótimas indicações de mercado e opções de compra. Os retroses de linhas e botões também serão adquiridos de empresas especializadas no ramo, para pesquisa de preços foram utilizados os mesmos critérios de seleção de fornecedores do tecido. Os custos foram descritos, com base na legalidade do método de custeio por absorção, para a precificação foram acrescidas as despesas do período exemplo: prólabore, encargos sociais, tributos e impostos, aluguel, água, luz, material de escritório entre outros.

A seguir, na tabela 1, detalha-se a composição e apuração do custo total, custo unitário e preço unitário de venda conforme critérios adotados pelos autores em observação as normas de contabilidade de custos e princípios contábeis geralmente aceitos.

Tabela 1: composição de apuração do custo total

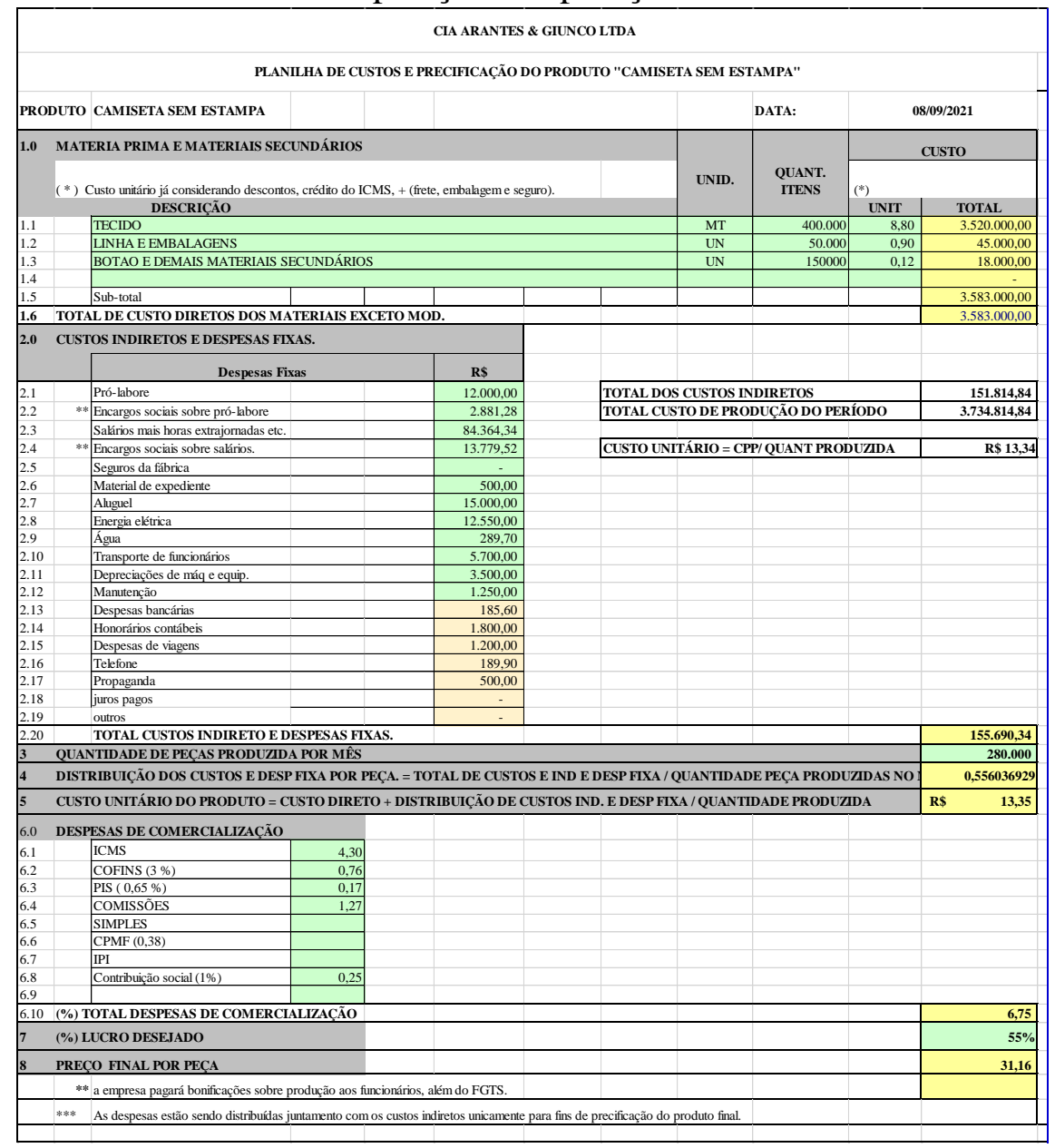




\section{CONSIDERAÇÕES FINAIS}

Por fim, através dos levantamentos de dados, processamento, identificação e mensuração dos custos de produção da empresa ARANTES \& GIUNCO LTDA, foi possível apropriar todos os custos ligados a produção, agregar as despesas fixas, calcular tributos e taxas sobre vendas, despesa comercial variável, margem de lucro desejada e determinação do preço unitário de venda de forma segura e eficaz, permitindo que o produto a seja comercializado pelo valor correto de forma a atender as necessidades da companhia quanto a geração de lucros e possibilidades de crescimento, bem como atender os clientes com produtos de qualidade a baixo custo com possibilidades de agregação de valores significativos e margens elevadas de lucros após customização das peças.

\section{REFERÊNCIAS}

BEUREN, Ilse Maria. Como elaborar trabalhos monográficos em contabilidade. 3. ed. São Paulo: Atlas, 2006

CREPALDI, Silvio Aparecido. Contabilidade de custos. 6. Rio de Janeiro Atlas 20171 recurso online ISBN 9788597014181.

LEONE, G. S. Custos: planejamento, implantação e controle. São Paulo: Atlas, 2000.

MARTINS, Eliseu. Contabilidade de Custos, 11 ed. São Paulo, Atlas, 2018.

NEVES, Silvério das; VICECONTI, Paulo Eduardo. Contabilidade de custos - um enfoque direto e objetivo. 11. ed. FRASE, 2013.

RIBEIRO, Osni Moura. Contabilidade de custos / Osni Moura Ribeiro - 5. ed. São Paulo: Saraiva, 2018.

https://www.dicio.com.br/precificacao/. Acessado em 08/09/2021. 